\title{
The relation between sea ice thickness and freeboard in the Arctic
}

\author{
V. Alexandrov ${ }^{1,2}$, S. Sandven ${ }^{2,3}$, J. Wahlin ${ }^{2}$, and O. M. Johannessen ${ }^{2}$ \\ ${ }^{1}$ Nansen International Environmental and Remote Sensing Center (NIERSC), 14th Line of Vasilevsky Island, 7, office 49, \\ 199034 St. Petersburg, Russia \\ ${ }^{2}$ Nansen Environmental and Remote Sensing Center (NERSC), Thormoehlensgate 47, 5006 Bergen, Norway \\ ${ }^{3}$ Department of Arctic Geophysics, University of Svalbard (UNIS), 9171 Longyearbyen, Norway
}

Received: 30 March 2010 - Published in The Cryosphere Discuss.: 22 April 2010

Revised: 6 September 2010 - Accepted: 11 September 2010 - Published: 20 September 2010

\begin{abstract}
Retrieval of Arctic sea ice thickness from CryoSat-2 radar altimeter freeboard data requires observational data to verify the relation between these two variables. In this study in-situ ice and snow data from 689 observation sites, obtained during the Sever expeditions in the 1980s, have been used to establish an empirical relation between thickness and freeboard of FY ice in late winter. Estimates of mean and variability of snow depth, snow density and ice density were produced on the basis of many field observations. These estimates have been used in the hydrostatic equilibrium equation to retrieve ice thickness as a function of ice freeboard, snow depth and snow/ice density. The accuracy of the ice thickness retrieval has been calculated from the estimated variability in ice and snow parameters and error of ice freeboard measurements. It is found that uncertainties of ice density and freeboard are the major sources of error in ice thickness calculation. For FY ice, retrieval of $\approx 1.0 \mathrm{~m}(2.0 \mathrm{~m})$ thickness has an uncertainty of $46 \%$ (37\%), and for MY ice, retrieval of $2.4 \mathrm{~m} \mathrm{(3.0} \mathrm{m)} \mathrm{thickness} \mathrm{has} \mathrm{an} \mathrm{uncertainty} \mathrm{of} 20 \%$ (18\%), assuming that the freeboard error is $\pm 0.03 \mathrm{~m}$ for both ice types. For MY ice the main uncertainty is ice density error, since the freeboard error is relatively smaller than that for FY ice. If the freeboard error can be reduced to $0.01 \mathrm{~m}$ by averaging measurements from CryoSat-2, the error in thickness retrieval is reduced to about $32 \%$ for a $1.0 \mathrm{~m}$ thick FY floe and to about $18 \%$ for a $2.4 \mathrm{~m}$ thick MY floe. The remaining error is dominated by uncertainty in ice density. Provision of improved ice density data is therefore important for accurate retrieval of ice thickness from CryoSat-2 data.
\end{abstract}

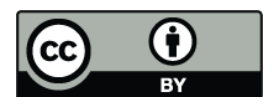

Correspondence to: V. Alexandrov (vitali.alexandrov@niersc.spb.ru)

\section{Introduction}

Satellite altimeter data can provide extensive spatial and temporal measurements of sea ice thickness through converting ice freeboard measurements to thickness by assuming hydrostatic equilibrium (Laxon, 1994; Laxon et al., 2003; Giles et al., 2008; Kwok et al., 2009). Use of satellite radar altimetry (RA) for measuring ice freeboard is based on experiments showing that the radar signal reflects from the snowice, rather than the air-snow interface (Beaven et al., 1995). Changes in temperature could cause changes in the snow pack, affecting the radar signal penetration to the snow/ice interface (Hallikainen and Winebrenner, 1992; Giles and Hvidegaard, 2006). Ice thickness has been determined in winter period i.e. between October and March in the Arctic (Laxon et al., 2003). Analysis of ERS and Envisat RA data from 1992 to present have resulted in a unique data set on ice thickness south of $81.5^{\circ} \mathrm{N}$, showing a significant thinning of the ice cover from 2007 to 2008 (Giles et al., 2008). The ice thickness estimates represent monthly mean values in typically $100 \times 100-\mathrm{km}$ grid with an expected error of 0.04-0.06 m (Miller et al., 2006). These ERS/Envisat sea-ice thickness time series will be extended by CryoSat-2, whose major objective is to measure trends in sea ice thickness over most of the Arctic over a period of five years. CryoSat-2 was launched in April 2010 and carries a RA, which operates in Synthetic Aperture Radar mode over sea ice, providing freeboard measurements with $250 \mathrm{~m}$ resolution along the satellite track (ESA, 2003).

Snow depth, snow density and ice density have a strong impact on the sea ice buoyancy and ice freeboard. Since the ice freeboard has to be multiplied by a factor that can be up to 10 for calculation of thickness, small errors in the input data lead to large errors in the ice thickness estimates (Rothrock, 1986). Another uncertainty is the assumption that radar echo originates from the snow/ice interface. Recent studies by Connor et al. (2009), where coincident laser

Published by Copernicus Publications on behalf of the European Geosciences Union. 
altimeter (LA) and RA measurements of sea ice are available, show that the radar signals are reflected from the ice/snow interface, while the laser signals are reflected from the top of the snow cover.

Studies have been done to estimate ice thickness from the IceSat LA data. They showed that the ice thickness has significantly decreased from 2007 to 2008, which is in agreement with analysis of RA data from Envisat (Kwok et al., 2009). Ideally, LA and RA data should be collected simultaneously in order to obtain direct estimates of the snow depth, as demonstrated in airborne campaigns (Leuschen and Raney, 2005; Connor et al., 2009). Simultaneous LA and RA satellite sensors are not planned during the CryoSat-2 mission, thus snow data on Arctic sea ice have to be obtained from climatic estimates and new field observations. Another possibility is to construct daily fields of snow depth using available climatology and snowfall from ECMWF meteorological products for partitioning the total freeboard into its snow and ice components, as described by Kwok and Cunningham (2008).

Use of the hydrostatic equilibrium equation to estimate ice thickness from freeboard data requires data on snow and ice density as well as snow depth, which exhibit regional and seasonal variability. Climatic snow cover data from Russian North Pole drifting stations have been published by Warren et al. (1999), but there are few available data sets that provide statistics on snow and ice density, snow depth, ice freeboard and thickness over large parts of the Arctic ice cover. Therefore, the main objective of this paper is to investigate the relation between ice freeboard and ice thickness using extensive in-situ measurements from Arctic field expeditions. First, an empirical relation between ice thickness and freeboard is derived from direct measurements during the Sever expeditions in the 1980s. Furthermore, published data on snow and ice densities are reviewed and errors are estimated. These data are used in the hydrostatic equilibrium equation to assess the relations between thickness and freeboard for first-year (FY) and multiyear (MY) ice. Finally, the error sources in ice thickness retrieval from freeboard measurements are discussed and recommendations for in-situ observations in forthcoming CryoSat-2 post-launch calibrationvalidation experiments are provided.

\section{Ice thickness and freeboard data from the Sever expeditions}

In-situ measurements of Arctic sea ice from the airborne Sever expeditions provide one of the most extensive data sets of sea ice and snow parameters collected over many years including 1928, 1937, 1941, 1948-1952, and 1954-1993 (Romanov, 1995). The total data set, including 3771 landings, was obtained from the World Data Center for Glaciology/National Snow and Ice Data Center (NSIDC), Boulder, Colorado (National Snow and Ice Data Center, 2004). In this study co-located observations of ice thickness, ice freeboard and snow depth are extracted and used to establish an empirical relation between these parameters. The Sever expeditions took place mainly from mid March to early May, when landing on ice floes was possible. Thus, the data represent late winter conditions before melting starts. Ice and snow thickness were measured on each landing point by drilling holes at 3-5 locations 150-200 $\mathrm{m}$ apart on the level ice along the runway. In addition, measurements were made at 10-20 sites on adjacent ice floes, which included deformed ice (Romanov, 1995). Ice freeboard measurements were obtained only in a subset of the total data set from the Sever expeditions. Data from 689 landings in the period February-May of 1980 1982, 1984-1986 and 1988, where freeboard measurements were included, have been used in this study.

The data from the 689 landings were divided into two groups. The so-called runway data represent level ice, and the off-runway data can include ridges and various types of deformed and level ice, located around the level ice. The freeboard data were obtained only for level ice. The data set spans the entire Eurasian Russian Arctic (Fig. 1a), where FY ice is prevalent. The accuracy of the ice thickness, freeboard and snow depth measurements is $0.01 \mathrm{~m}$. Comparison shows that runways have thinner ice with less snow cover than surrounding ice. The modal ice thickness for the runway data is about $0.7 \mathrm{~m}$, while it is more than $1 \mathrm{~m}$ for the off-runway data. Maximum thickness is about $2.60 \mathrm{~m}$ for the runway data and about $3.50 \mathrm{~m}$ for the off-runway data (Fig. 1b).

The ice thickness and freeboard measurements are presented in Fig. 1c, and show a linear increase in thickness vs. freeboard. There is a significant spread in the ice thickness for each freeboard value, with mean standard deviation of $\pm 0.20 \mathrm{~m}$. For freeboard below $0.15 \mathrm{~m}$ there are more than 30 data points $(N)$ for each freeboard interval. From 0.15 to $0.20 \mathrm{~m}, N$ decreases to less than 10 per interval. Freeboard measurements above $0.20 \mathrm{~m}$ were not included, because there were only $2-3$ data points in each interval. A linear regression equation between freeboard $\left(F_{i}\right)$ and average thickness $\left(H_{i}\right)$, derived from the data, is given by:

$H_{i}=8.13 F_{i}+0.37$.

Using this equation a modal freeboard of $0.1 \mathrm{~m}$ corresponds to ice thickness of $1.18 \pm 0.20 \mathrm{~m}$. The snow depth on the runway is less than $0.20 \mathrm{~m}$ in more than $95 \%$ of cases, while it can be up to $0.40 \mathrm{~m}$ in the off-runway data. The difference in snow depth between FY and MY ice affects the relation between freeboard and thickness. Equation (1) is applicable for level FY ice in the period March-May, but has to be modified for deformed FY and MY ice. Empirical relations between thickness and freeboard are not used to retrieve ice thickness from radar altimeter data, but they are important for studies of the variability in the relation under different ice and snow conditions. 


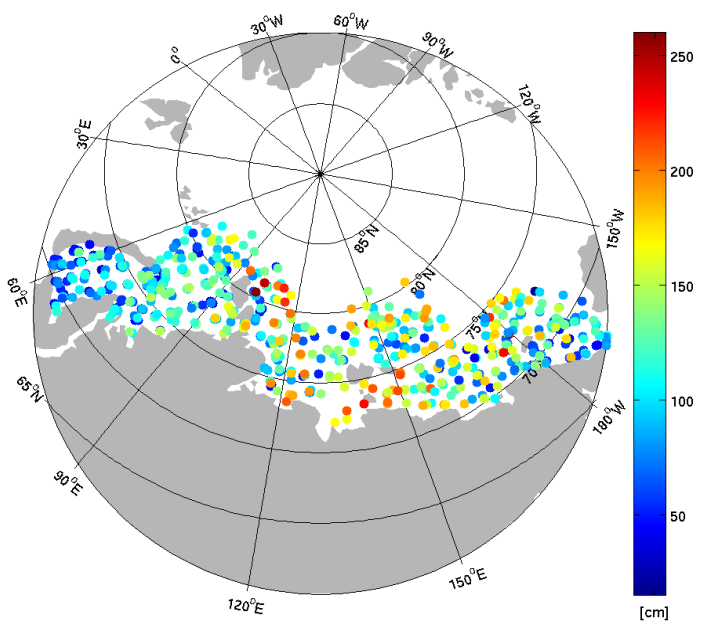

a)

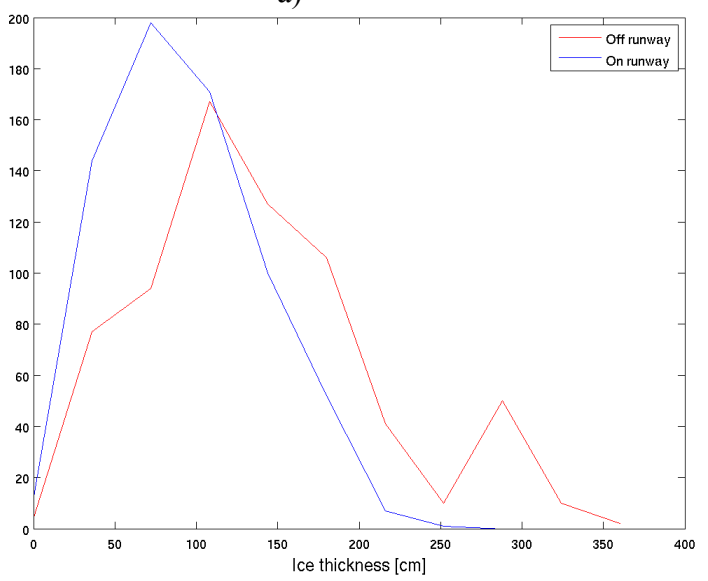

b)

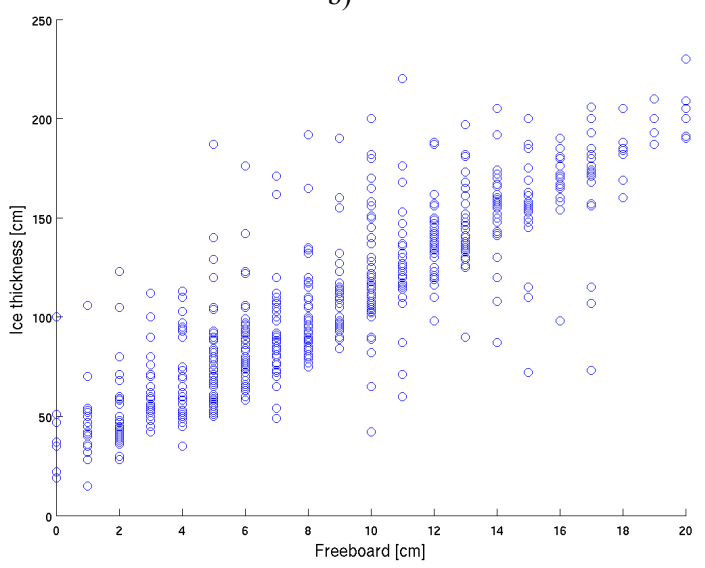

c)

Fig. 1. (a) Location of 689 ice thickness and freeboard measurements during the Sever aircraft landings on the Arctic sea ice in 1980s, where colors indicate thickness of level ice on runways; (b) histogram of ice thickness on level ice (on runway) and on characteristic ice types around the landing sites (off runway), (c) a scatterplot of ice thickness versus ice freeboard measurements on level ice.

\section{Snow and ice data}

\subsection{Snow depth and density}

Snow depth on the Arctic sea ice increases from a minimum in July-August to a maximum in April-May before the onset of summer melt (Radionov et al., 1996; Warren et al., 1999). On MY ice in the Central Arctic the snow depth is $0.35 \mathrm{~m}$ in May with an uncertainty of $0.06 \mathrm{~m}$ (Loshchilov, 1964; Warren et al., 1999). The snow depth on level FY ice is much smaller, typically between $0.05 \mathrm{~m}$ for ice thinner than $1.60 \mathrm{~m}$ and $0.08 \mathrm{~m}$ for ice thicker than $1.60 \mathrm{~m}$ (Romanov, 1995). Data from the Sever expeditions show a median snow depth on runways of $0.05 \mathrm{~m}$. The uncertainty of the snow depth is also $0.05 \mathrm{~m}$. The density of snow on MY ice in March-May is in the range of $310-320 \mathrm{~kg} \mathrm{~m}^{-3}$ (Romanov, 1995; Warren et al., 1999). The average and standard deviation of snow density on FY ice, calculated from the Sever data, is $324 \pm 50 \mathrm{~kg} \mathrm{~m}^{-3}$. The difference in snow properties between MY and FY ice is therefore related to snow depth, not to snow density.

\subsection{Ice density}

The density of gas-free sea ice can vary from 919 to $974 \mathrm{~kg} \mathrm{~m}^{-3}$ depending on the salinity (Cox and Weeks, 1982). The most important factor determining the ice density in low temperatures is the fractional volume of air bubbles (Schwerdtfeger, 1963; Wadhams, 2000), which can reduce the density to $840 \mathrm{~kg} \mathrm{~m}^{-3}$ (Weeks, 1976). Figure 2 shows a composite of ice density values for thin, FY and MY ice (Malmgren, 1927; Mobley et al., 1998; Kubishkin and Skutina, 2004; Schulson et al., 2006). The density values can vary significantly, and the methods used to estimate them have impact on the results. The following four methods can be used to estimate ice density: (i) measurement of mass and volume of a given ice body, (ii) displacement (submersion) technique, (iii) specific gravity technique, and (iv) freeboardthickness technique (Timco and Frederking, 1996). Each method has advantages and limitations.

The freeboard-thickness method was used in this study to calculate density of FY ice from the Sever data. Assuming that the sea ice is in hydrostatic equilibrium, ice density can be calculated as

$\rho_{i}=\rho_{\mathrm{w}}-\frac{\rho_{\mathrm{w}} F_{i}+\rho_{\mathrm{sn}} H_{\mathrm{sn}}}{H_{i}}$,

where $F_{i}$ is ice freeboard, $H_{i}$ is ice thickness, $H_{\mathrm{sn}}, \rho_{\mathrm{sn}}$ are the thickness and density of snow, and $\rho_{\mathrm{w}}$ is water density. The database of Sever data contains mean values of ice thickness, freeboard, and snow depth on runways for 689 landings. The fact that the survey areas were used as runways does not affect the measurements of snow depth, which were made on undisturbed surface. The mean snow density from the Sever data is $324 \mathrm{~kg} \mathrm{~m}^{-3}$. Water density is set to $1025 \mathrm{~kg} \mathrm{~m}^{-3}$. Using Eq. (2) ice density was calculated for each of the 


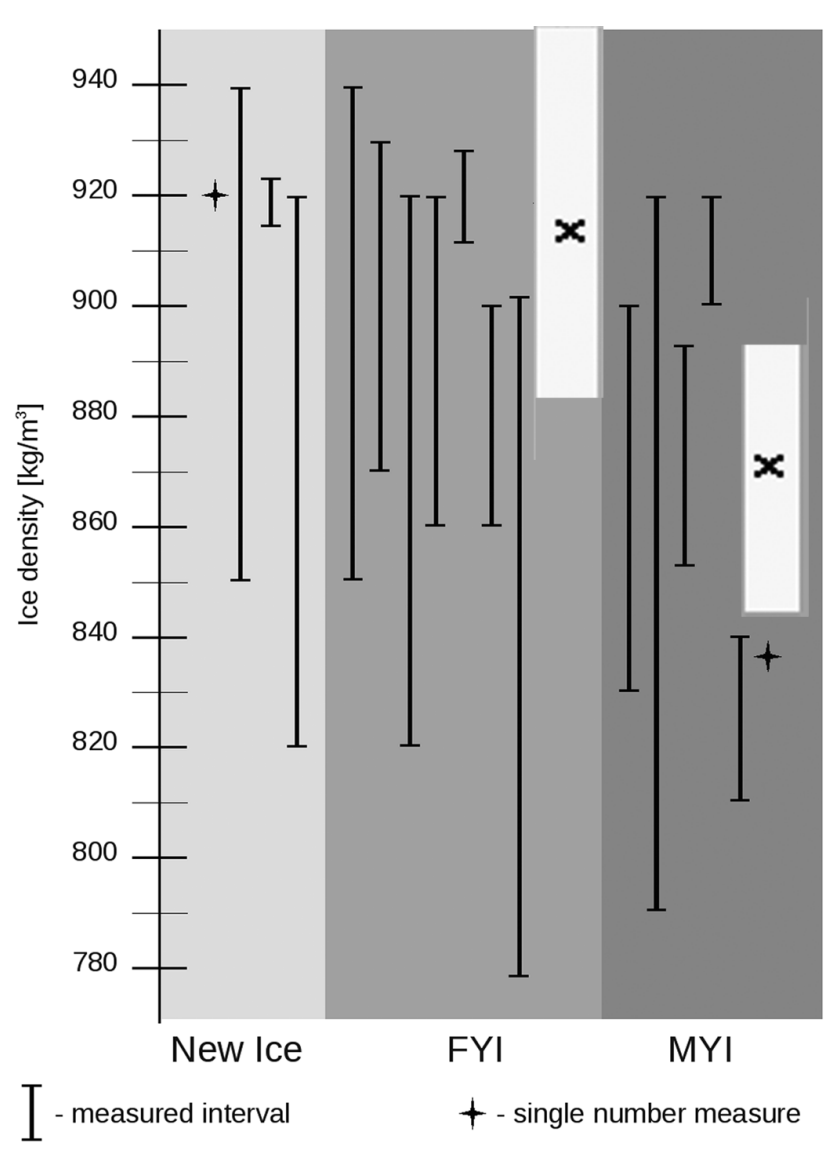

Fig. 2. A composite of sea ice density data measurement ranges obtained from Timco and Frederking (1995) and references there, as well as from papers by Malmgren (1927), Mobley et al. (1998), Kubishkin and Skutina (2004) and Schulson et al. (2006). The measurements were conducted using mostly mass/volume technique. The white column under FY ice represents the mean and standard deviation of density retrieved from the Sever data. The white column under MY ice represents the best estimate of mean and standard deviation of density from published material.

689 landings. The mean ice density for FY ice from the Sever data is $916.7 \pm 35.7 \mathrm{~kg} \mathrm{~m}^{-3}$. The hydrostatic assumption should be valid when many measurements are averaged over a large area. We assume that measurements, made at 3-5 locations 150-200 $\mathrm{m}$ apart, are representative for level ice on runway. A denser network of in situ measurements is necessary to verify the hydrostatic equilibrium assumption in areas of deformed ice.

Timco and Frederking (1996) reported that FY ice density is typically between 840 and $910 \mathrm{~kg} \mathrm{~m}^{-3}$, while MY ice density is between 720 and $910 \mathrm{~kg} \mathrm{~m}^{-3}$. Densities of MY and FY ice samples taken below the waterline are not significantly different, and both ice types have typical values between 900 and $940 \mathrm{~kg} \mathrm{~m}^{-3}$. For samples taken above the waterline, the MY ice has significantly lower density than FY ice. According to Khohlov (1978), the average density of the MY ice above the waterline is typically between $500-600 \mathrm{~kg} \mathrm{~m}^{-3}$. This difference is mainly due to the higher volume of airfilled pores in MY ice compared to FY ice (Onstott, 1992; Eicken et al., 1995). In this study we use a density of $550 \mathrm{~kg} \mathrm{~m}^{-3}$ for the upper layer $\left(\rho_{\mathrm{u}}\right)$ from Khohlov (1978) and a value of $920 \mathrm{~kg} \mathrm{~m}^{-3}$ for the lower layer $\left(\rho_{1}\right)$ to calculate an averaged weighed value for the MY ice density:

$\rho_{\mathrm{my}}=\rho_{\mathrm{l}}\left(1-F_{i} / H_{i}\right)+\rho_{\mathrm{u}} F_{i} / H_{i}$.

By inserting density values for the upper and lower layers, using typical freeboard $(0.3 \mathrm{~m})$ and thickness data $(2.9 \mathrm{~m})$ for MY ice, the bulk density of MY ice becomes $882 \pm 23 \mathrm{~kg} \mathrm{~m}^{-3}$. The uncertainty of MY-ice density was calculated as a weighted average of ice density uncertainties for its upper and lower layers. During winter, seawater density in most of the Arctic Ocean varies from 1024 to $1027 \mathrm{~kg} \mathrm{~m}^{-3}$ (Gorshkov, 1980; Timokhov and Tanis, 1997; Pavlov, 1998). In our calculations the density of sea water is set to $1025 \pm 0.5 \mathrm{~kg} \mathrm{~m}^{-3}$.

\section{Error estimates in ice thickness retrieval under hydrostatic equilibrium assumption}

Assuming that sea ice is in hydrostatic equilibrium with water, ice thickness can be calculated from the following equation where all variables on the right side have prescribed values:

$H_{i}=\frac{\rho_{\mathrm{w}}}{\left(\rho_{\mathrm{w}}-\rho_{i}\right)} F_{i}+\frac{\rho_{\mathrm{sn}}}{\left(\rho_{\mathrm{w}}-\rho_{i}\right)} H_{\mathrm{sn}}$.

The values of $\rho_{\mathrm{w}}, \rho_{i}, \rho_{\mathrm{sn}}$, and $H_{\mathrm{sn}}$ are based on statistics from many observations, while freeboard $\left(F_{i}\right)$ is a variable with values between 0.01 and $0.20 \mathrm{~m}$ for FY ice and from 0.21 to $0.50 \mathrm{~m}$ for MY ice. Assuming that the uncertainties are uncorrelated, the error in ice thickness $\left(\varepsilon_{r}^{2}\right)$ calculated from RA measurements of ice freeboard is given by (Giles et al., 2007):

$$
\begin{aligned}
& \varepsilon_{r}^{2}=\varepsilon_{F i}^{2}\left(\frac{\rho_{\mathrm{w}}}{\left(\rho_{\mathrm{w}}-\rho_{i}\right)}\right)^{2}+\varepsilon_{H_{\mathrm{sn}}}^{2}\left(\frac{\rho_{\mathrm{sn}}}{\left(\rho_{w}-\rho_{i}\right)}\right)^{2}+\varepsilon_{\rho_{\mathrm{sn}}}^{2}\left(\frac{H_{\mathrm{sn}}}{\left(\rho_{\mathrm{w}}-\rho_{i}\right)}\right)^{2} \\
& +\varepsilon_{\rho_{\mathrm{w}}}^{2}\left(\frac{F_{i}}{\left(\rho_{\mathrm{w}}-\rho_{i}\right)}-\frac{F_{i} \rho_{\mathrm{w}}}{\left(\rho_{\mathrm{w}}-\rho_{i}\right)^{2}}-\frac{H_{\mathrm{sn}} \rho_{\mathrm{sn}}}{\left(\rho_{\mathrm{w}}-\rho_{i}\right)^{2}}\right)^{2} \\
& +\varepsilon_{\rho_{i}}^{2}\left(\frac{F_{i} \rho_{\mathrm{w}}}{\left(\rho_{\mathrm{w}}-\rho_{i}\right)^{2}}+\frac{H_{\mathrm{sn}} \rho_{\mathrm{sn}}}{\left(\rho_{\mathrm{w}}-\rho_{i}\right)^{2}}\right)^{2},
\end{aligned}
$$

where $\varepsilon_{\rho_{i}}, \varepsilon_{\rho_{\mathrm{w}}}, \varepsilon_{\rho_{\mathrm{sn}}}$ are the uncertainties in the density of ice, water and snow, $\varepsilon_{H_{\mathrm{sn}}}$ is the uncertainty in the snow height, and $\varepsilon_{F_{i}}$ is the uncertainty in the ice freeboard, measured by RA. Typical values and uncertainties of ice freeboard (Giles et al., 2007), seawater, snow and sea ice parameters, estimated in Sect. 3, are presented in Table 1.

After substituting the typical values of snow, ice, and water parameters in the hydrostatic equilibrium equation, ice thickness is given as a linear function of freeboard for FY ice by:

$H_{i}=9.46 F_{i}+0.15$, 
and for MY ice by:

$H_{i}=6.24 F_{i}+1.07$.

The uncertainty values in Table 1 are inserted in the error Eq. (5), and the results are presented in Fig. 3, where the error in ice thickness retrieval is plotted as a function of freeboard. The calculations are based on a freeboard error of $0.03 \mathrm{~m}$. The influence of changes in snow and seawater densities is insignificant. The error in thickness retrieval is dominated by the freeboard error for thin FY ice, while the effect of the ice density uncertainty increases as the freeboard increases. The thickness of FY ice with a freeboard of $0.10 \mathrm{~m}$ is $1.10 \pm 0.48 \mathrm{~m}$ (error $\approx 44 \%$ ), whereas a freeboard of $0.20 \mathrm{~m}$ gives a thickness of $2.04 \pm 0.75 \mathrm{~m}$ (error $\approx 37 \%$ ). For MY ice, freeboards of 0.21 and $0.30 \mathrm{~m}$ give thicknesses of $2.38 \pm 0.48 \mathrm{~m}$ (error $\approx 20 \%$ ) and $2.94 \pm 0.54 \mathrm{~m}$ (error $\approx 18 \%$ ), respectively. The ice density error is the dominant term in the thickness retrieval. It is found that uncertainties of ice density and freeboard measurement are the major sources of error in the ice thickness calculation, while the error due to uncertainty in snow depth is small.

The error in the thickness retrieval is smaller for MY ice compared to FY ice for two reasons: (1) the relative error in freeboard measurement is smaller for MY ice than for FY ice, and (2) the uncertainty in ice density is smaller for MY ice compared to FY ice based on the data in Table 1. However, the error in MY density is not well documented. As it was discussed, the FY ice density used in the error analysis is assumed to be in the upper range of typical values. Its density is expected to become lower, if we include both level and deformed ice.

The error estimates shown in Fig. 3 are valid for the late winter period (March-May). The snow depth has strong seasonal variability, so the error estimates will be different for the other seasons.

These estimates also show that constant freeboard-tothickness ratios can be used for ice thickness calculation from RA data in late winter, when snow loading does not change substantially.

\section{Comparison with other relations between ice thickness and freeboard}

The relation between ice thickness and freeboard has been investigated by Mironov and Sen'ko (1995), who analyzed measurements of ice thickness, ice draft, snow depth and density conducted across the Arctic Ocean from June 1987 to August 1988 at the North Pole-29 drifting station. They established the following relations:

$H_{i}=11.0 F_{i}-0.12$

for FY ice in the period October to May, and

$H_{i}=15.3 F_{i}-0.66$,

for MY ice in the period December to May.
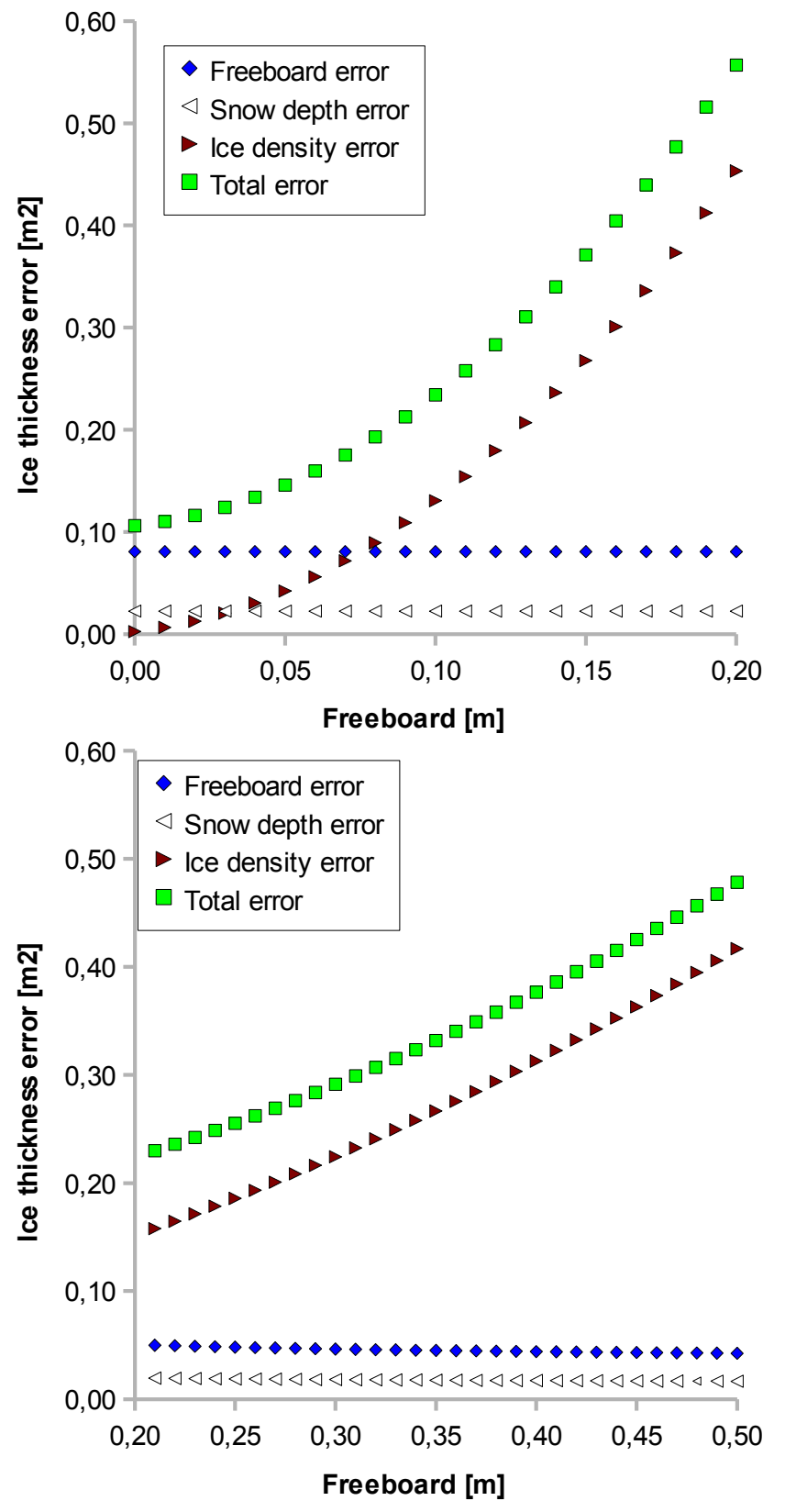

Fig. 3. Error terms contributing to uncertainty in ice thickness retrieval from freeboard measurements for first-year (left) and multiyear (right) ice. The prescribed error of ice freeboard is $0.03 \mathrm{~m}$.

By analyzing airborne lidar data and submarine sonar data, Wadhams $(1992,2000)$ has found an empirical relation between the freeboard and draft of thick MY ice north of Greenland, which corresponds to the following relation between thickness and freeboard:

$H_{i}=9.04 F_{i}$.

Laxon et al. (2003) and Giles et al. (2007, 2008) have calculated ice thickness using the hydrostatic equilibrium equation 
Table 1. Typical values and uncertainties of snow and ice density and snow depth for late winter conditions. The freeboard data are prescribed input to the hydrostatic equilibrium equation.

\begin{tabular}{llllll}
\hline \multirow{2}{*}{ Parameter } & \multicolumn{3}{c}{ Ice type } \\
\cline { 2 - 3 } \cline { 5 - 6 } \cline { 5 - 6 } & \multicolumn{2}{c}{ FY ice } & & \multicolumn{2}{c}{ MY ice } \\
\cline { 2 - 3 } \cline { 5 - 6 } & Typical value & Uncertainty & & Typical value & Uncertainty \\
\hline Ice freeboard, $\mathrm{m}$ & $0.01-0.2^{\mathrm{a}}$ & $0.03^{\mathrm{b}}$ & & 0.3 & $0.03^{\mathrm{b}}$ \\
Snow depth, $\mathrm{m}$ & 0.05 & 0.05 & & 0.35 & 0.06 \\
Ice density, $\mathrm{kg} \mathrm{m}^{-3}$ & $916.7^{\mathrm{c}}$ & $35.7^{\mathrm{c}}$ & & $882^{\mathrm{d}}$ & $23^{\mathrm{d}}$ \\
Snow density, $\mathrm{kg} \mathrm{m}^{-3}$ & 324 & 50 & & 320 & 20 \\
\hline
\end{tabular}

a The freeboard varies with thickness and age of the FY ice.

${ }^{b}$ Freeboard is a free variable and the uncertainty estimates are used as example of realistic numbers.

c Analysis of level FY ice from the Sever data.

${ }^{\mathrm{d}}$ Based on data from literature.

and prescribed values of water and ice densities and snow loading climatology from Warren et al. (1999).

Calculations using Eqs. (1), (6)-(10), combined with direct measurements of thickness and freeboard from some recent expeditions, are presented in Fig. 4. The graphs show calculated ice thickness for given freeboard values up to $0.5 \mathrm{~m}$, and do not represent the errors in thickness when using the hydrostatic equilibrium equation with variable snow depth and density. The Sever data are marked by the black line representing the linear regression Eq. (1) as well as a grey zone, corresponding to \pm standard deviation. The asterisks indicate individual measurements during the expeditions in the Barents Sea area onboard R/V Lance in 2004 and R/V M. Somov in 2006.

Significant spread in the relations implies that there are errors in the data used to establish these relations. There is a reasonable agreement between the empirical relations for FY ice. For example, a freeboard measurement of $0.10 \mathrm{~m}$ corresponds to a thickness estimate of $1.18 \pm 0.2 \mathrm{~m}$, using mean and standard deviation of the Sever data. When the effect of uncertainty in freeboard measurement of $\pm 0.03 \mathrm{~m}$ is included, the overall error in thickness retrieval will be about $\pm 0.5 \mathrm{~m}$. This is in agreement with the error analysis based on Eq. (5).

There is more spread between the relations for MY ice, and it is difficult to assess their validity. The relation by Wadhams et al. (1992) is based on data north of Greenland, where the MY ice is heavily deformed, while the relation by Mironov and Sen'ko (1995) is based on data from the Central Arctic, where ice is less deformed. Estimation of thickness from a freeboard of $0.3 \mathrm{~m}$ gives $3.93 \mathrm{~m}$ according to Eq. (9). This estimate seems to be in the upper range of expected values. If Eq. (7) is assumed to be more realistic and the effect of an uncertainty in freeboard measurement of $\pm 0.03 \mathrm{~m}$ is included, the thickness retrieval will be $2.94 \pm 0.54 \mathrm{~m}$.

Use of various values of ice density and snow loading substantially influences calculation of sea ice thickness.

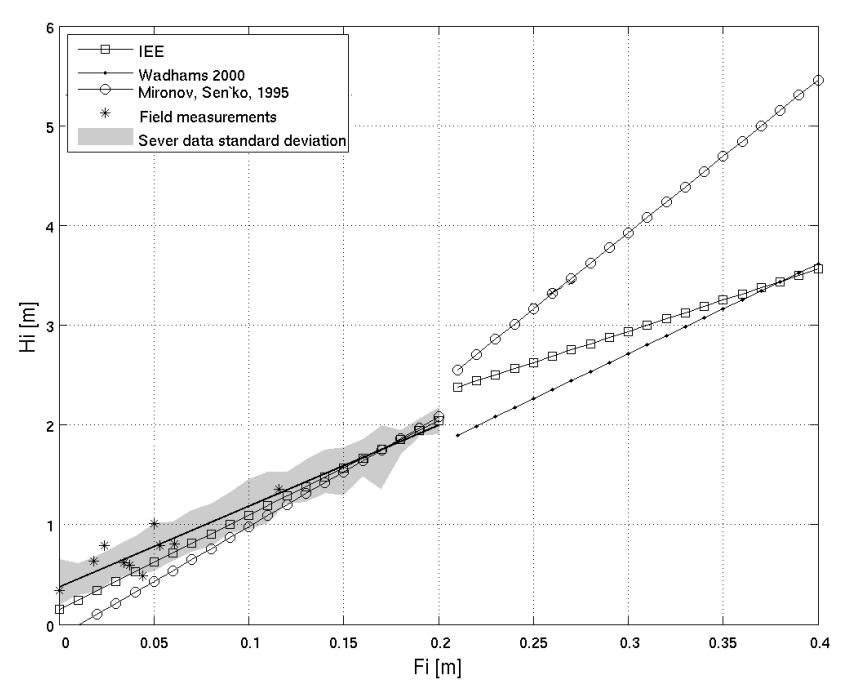

Fig. 4. Relation between ice thickness and ice freeboard based on measurements from the Sever expeditions (Eq. 1, standard deviation is shown as the grey zone); North Pole-29 drifting station (Mironov and Sen'ko, 1995) (Eqs. 8 and 9); Wadhams et al., 1992 (Eq. 10); and hydrostatic equilibrium equation (IEE) for FY and MY ice used in this study (Eqs. 6 and 7). The asterisks represent other direct measurements of thickness and freeboard obtained by the authors in 2004 and 2006.

However, the uncertainty of a point measurement of ice thickness, as it is described here, is expected to be greater than the error in the trend. Our calculations show that the trends in ice thickness, estimated using relations under study, are not substantially different. 


\section{Conclusions}

In this study the technique of ice thickness retrieval from freeboard measurements, which will be provided by the CryoSat-2 RA, has been investigated using in-situ data from field expeditions and published results. An empirical relation derived from measurements on 689 sites in the period March-May allows retrieval of FY ice thickness from freeboard values in the range of $0.01-0.20 \mathrm{~m}$. The average snow depth on the FY ice, calculated from the Sever data, amounts to $0.05 \mathrm{~m}$, which is significantly less than that on MY ice. Snow density estimate of $324 \pm 50 \mathrm{~kg} \mathrm{~m}^{-3}$ is in agreement with other studies for both FY and MY ice.

Data on snow and ice density have been reviewed in order to estimate mean values and typical variability for assessment of errors in ice thickness retrieval from freeboard data. The density of level FY ice, estimated using the hydrostatic equilibrium equation and the Sever data, amounts to $916.7 \pm 35.7 \mathrm{~kg} \mathrm{~m}^{-3}$. This estimate is in the upper part of the density range for FY ice according to the published results. The density of MY ice, calculated as the weighted average of its upper and lower layers, decreases from 887 to $876 \mathrm{~kg} \mathrm{~m}^{-3}$, when its thickness increases from 2.4 to $4.2 \mathrm{~m}$. Previous studies show that FY ice density has realistic values between $840 \mathrm{~kg} \mathrm{~m}^{-3}$ and $910 \mathrm{~kg} \mathrm{~m}^{-3}$, while MY ice covers a wider range from $720 \mathrm{~kg} \mathrm{~m}^{-3}$ to $910 \mathrm{~kg} \mathrm{~m}^{-3}$ (Timco and Frederking, 1995). Different densities for FY and MY ice should be used routinely to calculate sea ice thickness from laser and radar measurements of freeboard.

The mean values and uncertainties of snow depth and ice and snow densities, determined for FY ice and MY ice, were used to calculate the total error in ice thickness retrieval from freeboard measurements using the hydrostatic equilibrium equation. The error in thickness retrieval due to the uncertainty in snow depth is much less than that due to the uncertainties in ice density and freeboard, using estimates for late winter conditions (March-May). The ice density error increases with increasing freeboard, while the error due to freeboard uncertainty is nearly constant. Uncertainties of thickness retrieval amount to $\approx 46 \%$ for $\approx 1.0 \mathrm{~m}$ thick FY ice and to $\approx 20 \%$ for $\approx 2.4 \mathrm{~m}$ thick MY ice. If the MY thickness increases to $\approx 3.0 \mathrm{~m}$ the error is reduced to $\approx 18 \%$. These estimates are based on a $\pm 0.03 \mathrm{~m}$ error in the freeboard measurements. The error in freeboard measurements is the main uncertainty factor for FY ice thinner than $0.8 \mathrm{~m}$, while ice density becomes the main error source for thicker FY ice and all MY ice. If the freeboard error can be reduced to $0.01 \mathrm{~m}$, the error in thickness retrieval is reduced to about $32 \%$ for a $1.0 \mathrm{~m}$ thick FY floe and to about $18 \%$ for a $2.4 \mathrm{~m}$ thick MY floe.

A synthesis of investigated relations between ice freeboard and thickness has been established based on direct measurements from several field campaigns. There is a general linear increase in thickness as function of freeboard, but the spread of the relations is significant. For FY ice the relations are fairly consistent, whereas for MY ice there are inconsistencies among several of them. These relations are based on data obtained in different parts of the Arctic, where the degree of ice deformation is highly variable. Further studies are necessary to clarify the freeboard-thickness relation for MY ice, which implies that new data on freeboard, thickness, density and snow cover should be collected. It is particularly important to collect separate data sets for MY and FY ice. The results of the error analysis of the freeboard-thickness relation are applicable to the retrieval of ice thickness from CryoSat-2 altimeter data in late winter, if constant freeboardto-thickness ratios are assumed.

The present analysis is based on data for the winter months only, and similar analyses should be conducted for the other seasons. There is a general lack of in-situ snow and ice measurements in the Arctic, and new observing systems are therefore necessary to provide data for validation of the ice thickness retrievals from CryoSat-2, expected to be in operation for five years from 2010.

Acknowledgements. This work was supported by the EU FP6 project DAMOCLES (Developing Arctic Modelling and Observing Capabilities for Long-term Environment Studies, no. 018509), the Research Council of Norway (project No. 178916/S30 Ice-oceanatmosphere research in Svalbard using satellite and field data promotion of Russian and Norwegian $\mathrm{PhD}$ cooperation), and the ESA Prodex project "CryoSat sea ice validation and process studies in the European Arctic" (contract No. C90318). The Sever data are provided by World Data Center for Glaciology/National Snow and Ice Data Center, University of Colorado, Boulder, Colorado.

Edited by: W. Lipscomb

\section{References}

Beaven, S. G., Lockhart, G. L., Gogineni, S. P., Hosseinmostafa, A. R., Jezek, K., Gow, A. J., Perovich, D. K., Fung, A. K., and Tjuatja, S.: Laboratory measurements of radar backscatter from bare and snow-covered saline ice sheets, Int. J. Remote Sens., 16(5), 851-876, 1995.

Connor, L. N., Laxon, S. W., Ridout, A. L., Krabill, W. B., and McAdoo, D. C.: Comparison of Envisat radar and airborne laser altimeter measurements over Arctic sea ice, Remote Sens. Environ., 113, 563-570, 2009.

Cox, G. F. N. and Weeks, W. F.: Equations for determining the gas and brine volumes in sea ice samples, CRREL Report 82-30, Hanover, NH, 1982.

Eicken, H., Lensu, M., Lepparanta, M., Tucker, W. B., Gow, A. J., and Salmela, O.: Thickness, structure and properties of level summer multiyear ice in the Eurasian sector of the Arctic Ocean, J. Geophys. Res., 100, 22697-22710, 1995.

ESA: CryoSat Science Report, ESA SP-1272, 56 pp., 2003.

Giles, K. A. and Hvidegaard, S. M.: Comparison of spaceborne radar altimetry and airborne laser altimetry over sea ice in the Fram Strait, Int. J. Remote Sens., 27(15), 3105-3113, 2006. 
Giles, K. A., Laxon, S. W., Wingham, D. J., Wallis, D. W., Krabill, W. B., Leuschen, C. J., McAdoo, D., Manizade, S. S., and Raney, R. K.: Combined airborne laser and radar altimeter measurements over the Fram Strait in May 2002, Remote Sens. Environ., 111, 182-194, 2007.

Giles, K. A., Laxon, S. W., and Ridout, A. L.: Circumpolar thinning of Arctic sea ice following the 2007 record ice extent minimum, Geophys. Res. Lett., 35, L22502, doi:10.1029/2008GL035710, 2008.

Gorshkov, S. G.: Atlas of the oceans, The Arctic Ocean, USSR Navy Publishing House, 1980.

Hallikainen, M. and Winebrenner D. P.: The physical basis for sea ice remote sensing, in: Microwave Remote Sensing of Sea Ice, edited by: Carsey, F. D., American Geophysical Union, Geophysical Monograph No. 68, Washington DC, 29-46 pp., 1992.

Khohlov, G. P.: Physico-chemical characteristics of the upper layers of different sea ice types in the area near of "NP-22" drifting station, Trudy Arkticheskogo i Antarkticheskogo Instituta, 359, 4-12, 1978 .

Kubishkin, N. V. and Skutina, Y. A.: Changes of temperature, salinity, and density of level sea ice in spring period according to expedition studies in the Pechora Sea, Trudy Arkticheskogo i Antarkticheskogo Instituta, 449, 104-123, 2004.

Kwok, R. and Cunningham, G. F.: ICESat over Arctic sea ice: Estimation of snow depth and ice thickness, J. Geophys. Res., 113, C08010, doi:10.1029/2008JC004753, 2008.

Kwok, R., Cunningham, G. F., Wensnahan, M., Rigor, I., Zwally, H. J., and Yi, D.: Thinning and volume loss of the Arctic Ocean sea ice cover: 2003-2008, J. Geophys. Res., 114, C07005, doi:10.1029/2009JC005312, 2009.

Laxon, S. W.: Sea ice altimeter processing scheme at the EODC, Int. J. Remote Sens., 15(4), 915-924, 1994.

Laxon, S. W., Peacock, N., and Smith, D.: High interannual variability of sea ice thickness in the Arctic region, Nature, 425, 947 949, 2003

Leuschen, C. J. and Raney, R. K.: Initial results of data collection by the APL D2P Radar Altimeter over land and sea ice.,Johns Hopkins APL Technical Digest, 26, 114-122, 2005.

Loshchilov, V. S.: Snow cover on the ice of the central Arctic, Problemy Arktiki i Antarktiki, 17, 36-45, 1964.

Malmgren, F.: On the properties of sea-ice, in: The Norwegian North polar expedition with the "Maud" 1918-1925, Scientific results, A/s John Griegs Boktrykkeri, Bergen, 1(5), 1-67, 1927.

Miller, P. A., Laxon, S. W., Feltham, D. L., and Cresswell, D. J.: Optimization of sea ice model; using basinwide observations of Arctic sea ice thickness, extent and velocity, J. Climate, 19, 1089-1108, 2006.

Mironov, Y. U. and Sen'ko, N. P.: About relation between ice thickness and ice draft, Trudy Arkticheskogo i Antarkticheskogo Instituta, 435, 47-54, 1995.
Mobley, C. D., Cota, G. F., Grenfell, T. C., Maffione, R. A., Scott Pegau, W., and Perovich, D. K.: Modeling light propagation in sea ice, IEEE T. Geosci. Remote, 36(5), 1743-1749, 1998.

National Snow and Ice data Center: Morphometric characteristics of ice and snow in the Arctic Basin: aircraft landing observations from the Former Soviet Union, 1928-1989, compiled by Romanov, I. P., National Snow and Ice Data Center, Digital media, Boulder, CO, 2004.

Onstott, R. G.: SAR and scatterometer signatures of sea ice, in: Microwave Remote Sensing of Sea Ice, Geophysical Monograph No. 68, American Geophysical Union, Washington, DC, 73-104, 1992.

Pavlov, V. K.: Circulation in ice-covered waters, in: Physics of ice-covered waters, vol. 2, Helsinki University Printing House, Helsinki, 447-482, 1998.

Radionov, V. F., Bryazgin, N. N., and Aleksandrov, Y. I.: The snow cover of the Arctic Basin, Gidrometeoizdat, St. Petersburg, 1996.

Romanov, I. P.: Atlas of ice and snow of the Arctic Basin and Siberian Shelf seas, Backbone Publishing Company, 1995.

Rothrock, D. A.: Ice thickness distribution - measurement and theory, in: The Geophysics of Sea Ice, Plenum Press, New York and London, 551-576, 1986.

Schulson, E. M., Fortt, A. L., Iliescu, D., and Renshaw, C. E.: Failure envelope of first-year Arctic sea ice: The role of friction in compressive fracture, J. Geophys. Res., 111, C11S25, doi:10.1029/2005JC003235, 2006.

Schwerdtfeger, P.: The thermal properties of sea ice, J. Glaciol., 4, 789-907, 1963.

Timco, G. W. and Frederking, R. M. W.: A review of sea ice density, Cold Reg. Sci. Technol., 24, 1-6, 1996.

Timokhov, L. and Tanis, F.: Arctic Climatology Project, Environmental Working Group Joint U.S.-Russian Atlas of the Arctic Ocean - winter period, Environmental Research Institute of Michigan in association with the National Snow and Ice Data Center, Ann Arbor, MI, CD-ROM, 1997.

Wadhams, P., Tucker III, W. B., Krabill, W. B., Swift, R. N., Comiso, J. C., and Davis, R. N.: Relationship between sea ice freeboard and draft in the Arctic Basin, and implication for ice thickness monitoring, J. Geophys. Res., 97(C12), 20325-20334, 1992.

Wadhams, P.: Ice in the Ocean, Gordon and Breach Science Publishers, 2000

Warren, S. G., Rigor, I. G., Untersteiner, N., Radionov, V. F., Bryazgin, N. N., Aleksandrov, Y. I., and Colony, R.: Snow depth on Arctic Sea Ice, J. Climate, 12, 1814-1829, 1999.

Weeks, W. F.: Sea ice properties and geometry, AIDJEX Bulletin, 34, 137-172, 1976. 